\title{
Study on the subsurface damage mechanism of optical quartz glass during single grain scratching
}

\author{
Li Ming ${ }^{1}$,Xiaoguang Guo ${ }^{1}$, Ruifeng Zhai ${ }^{1}$, Xichun Luo $^{2}$,Renke Kang ${ }^{1}$, Zhuji Jin ${ }^{1}$, \\ Dongming $\mathrm{Guo}^{1}$
}

1 Key Laboratory for Precision and Non-Traditional Machining Technology of Ministry of Education, Dalian University of Technology, Dalian 116024, China. 2 Centre for Precision Manufacturing, Department of Design, Manufacture and Engineering Management, University of Strathclyde, Glasgow G1 1XJ, UK

\section{Corresponding Author: Xiaoguang Guo, E-mail: guoxg@ @lut.edu.cn Corresponding Author: Xichun Luo, E-mail: xichun.luo@strath.ac.uk}

Abstract: The single grain scratching SPH simulation model was established to study the subsurface damage of optical quartz glass. Based on the analysis of the stress, strain and scratching force during scratching, the generation and propagation of subsurface cracks were studied by combining with the scratch elastic stress field model. The simulation results show that the cracks generate firstly at the elastic-plastic deformation boundary in front of the grain $\left(\phi=28^{\circ}\right)$ due to the influence of the maximum principal tensile stress. During the scratching process, the median crack closes to form the subsurface damage by extending downward, the lateral crack promotes the brittle removal of the material by extending upward to the free surface, and microcracks remain in the elastic-plastic boundary at the bottom of the scratch after scratching. The depth of subsurface crack and plastic deformation increases with rising scratching depth. The increase of scratching speed leads to the greater dynamic fracture toughness, accompanied by a significant decrease of the maximum depth of subsurface crack and the number of subsurface cracks. The subsurface residual stress is concentrated at the bottom of the scratch, and the residual stress on both sides of the scratch surface would generate and propogate the Hertz crack. When the scratching depth is less than $1.5 \mu \mathrm{m}$ or the scratching speed is greater than $75 \mathrm{~m} / \mathrm{s}$, 
the residual stress value and the depth of residual stress are relatively small. Finally, the scratching experiment was carried out. The simulation analysis is verified to be correct, as the generation and propagation of the cracks in the scratching experiment are consistent with the simulation analysis and the experimental scratching force indicates the same variation tendency with the simulation scratching force. The research results in this paper could help to restrain the subsurface damage in grinding process.

Key words: Single grain scratching; SPH; Scratch elastic stress field model; Subsurface crack; Subsurface residual stress

\section{Introduction}

Optical quartz glass is an amorphous material composed of high concentration silica. Due to its unique structural characteristics, optical quartz glass has superior optical, physical and, chemical properties, such as high strength, high temperature resistance, good chemical stability. It is widely used in optical fiber communication, aerospace, laser nuclear technology, semiconductor and other fields [1-3]. However, the optical quartz glass is a typical hard-brittle and difficult-to-machine material [4-6], the brittle fracture and microcracks inside the material can be easily generated during machining because of its high hardness, brittleness and low fracture toughness.

At present, the research on hard-brittle materials mainly focused on improving the ductile machining capability [7-9] and reducing or even eliminating the subsurface damage [10-12]. Existing theoretical studies have shown that when the cutting depth is less than a certain value, hard-brittle materials could exhibit obvious plastic flow behavior under high hydrostatic pressure [13]. Bifano et al. [14] proposed the critical cutting depth calculation formula of $d_{c}$ based on the Griffth crack propagation criterion and the principle of material brittleness measurement in the indentation experiment. Muhammad et al. [15] analyzed the plastic-brittle transition from an energy perspective, pointing out that the energy expended in the brittle and ductile machining modes is a function of the intrinsic properties of the working material, tool geometry and the process parameters. Guo et al. [16] achieved ductile grinding of hard-brittle materials by analyzing the mechanism of brittle-ductile transition and strictly controlling the grinding conditions. In the ductile machining, the hard-brittle materials undergo plastic deformation without brittle fracture, which is considered to be the most effective machining method to achieve high-quality machined surfaces of hard-brittle materials. However, due to 
the small critical cutting depth, it is highly difficult to realize the ductile machining of hard-brittle materials. Therefore, it is critical to focus on how to reduce or even eliminate the subsurface damage.

In the process of grinding and polishing, it is inevitable to incur subsurface damage to hard-brittle materials. Optical quartz glass is a kind of short-range ordered and long-range disordered amorphous material, with its subsurface damage including subsurface cracks and subsurface residual stress [17]. The stress state reflects the deformation of the material in real time during the actual machining process. Johnson [18] proposed a model to describe the elastic-plastic stress field beneath the indenter in ideal elastic-plastic material based on the indentation experiment where the influence of normal load is only considered. By introducing blister field model, Yoffe [19] established a perfect elastic stress field model of indentation, which well explains the effect of residual stress on material deformation. Ahn et al. [20] proposed the Sliding Blister Field Model (SBFM) as an extension of the indentation elastic stress field model, adding tangential load stress field to the model established by Yoffe [19] . Some scholars have studied the material removal mechanism [21], crack generation and propagation [22-23] of hard-brittle materials through these elastic stress field models. However, these studies only analyzed the formation of cracks through theoretical calculations, without intuitive demonstration of how cracks evolves and considering the effect of scratching speed on crack propagation. In order to better investigate the subsurface damage of optical quartz glass, the meshless method-smoothed particle hydrodynamics (SPH) is used to focus on the crack propagation and residual stress during the machining. It is adopted by many scholars to study a variety of materials [24-26] and turns out to be effective, as is indicated by the ideal results.

In this paper, the subsurface damage of optical quartz glass was studied by establishing a single grain scratching SPH simulation model. By analyzing the stress and strain during the scratching process and combining with the scratch elastic stress field model, the generation and propagation of subsurface cracks were studied in detail. The influence of scratching depth and scratching speed on crack formation and scratching force was discussed, and the subsurface residual stress was also analyzed. The scratching experiment was carried out. The simulation analysis was verified to be correct with the experimental results basically consistent with the simulation results. The research results in this paper could provide a theoretical basis for reducing the subsurface damage in grinding process.

\section{Scratch elastic stress field model}

In the grinding process, the mutual movement between the grain and workpiece can be simplified as a scratching 
process [27-29]. The scratch elastic stress field model was proposed by Ahn et al. [20], which mainly includes Boussinesq field stress field caused by normal load, Cerruti field stress field caused by tangential load, and blister field stress field caused by residual stress. The geometric characteristics of the stress field cannot be well described because of the complicated formulas of these models in rectangular coordinate system. In order to better describe the stress field during scratching, the elastic stress field model in this paper was established in the cylindrical coordinate system $(r, z, \theta)$, as shown in Fig. 1. The scratching depth is $d$, and the scratching direction is parallel to the workpiece surface.

In the cylindrical coordinate system, the expression of Boussinesq field and Cerruti field analytical model [30] are as follows:

$$
\left\{\begin{array}{c}
\alpha_{\mathrm{rr}}=\frac{F_{n}}{2 \pi \rho^{2}}\left[\frac{1-2 v}{1+\cos \phi}-3 \sin ^{2} \phi \cos \phi\right]+\frac{F_{t} \cos \theta}{2 \pi \rho^{2}}\left[\frac{(1-2 v) \sin \phi}{(1+\cos \phi)^{2}}-3 \sin ^{3} \phi\right] \\
\alpha_{\theta \theta}=\frac{F_{n}}{2 \pi \rho^{2}}\left[(1-2 v)\left(\cos \phi-\frac{1}{1+\cos \phi}\right)\right]+\frac{F_{t} \cos \theta}{2 \pi \rho^{2}}\left[(1-2 v) \sin \phi\left(1-\frac{1}{(1+\cos \phi)^{2}}\right)\right] \\
\alpha_{z z}=\frac{F_{n}}{2 \pi \rho^{2}}\left(-3 \cos ^{3} \phi\right)-\frac{F_{t} \cos \theta}{2 \pi \rho^{2}}\left(3 \sin \phi \cos ^{2} \phi\right) \\
\alpha_{r z}=\frac{F_{n}}{2 \pi \rho^{2}}\left(-3 \sin \phi \cos ^{2} \phi\right)-\frac{F_{t} \cos \theta}{2 \pi \rho^{2}}\left(3 \sin ^{2} \phi \cos \phi\right) \\
\alpha_{r \theta}=\frac{F_{t} \sin \theta}{2 \pi \rho^{2}}\left[\frac{(1-2 v) \sin \phi}{(1+\cos \phi)^{2}}\right] \\
\alpha_{z \theta}=0
\end{array}\right.
$$

Where $F_{n}$ is normal load, $F_{t}$ is tangential load, $v$ is Poisson's ratio, $r=\rho \sin \phi, z=\rho \cos \phi$. The analytical model can be described as a general formula by

$$
\alpha_{i j}=\frac{F_{n}}{2 \pi \rho^{2}} f_{i j}(\phi, \theta)_{v}+\frac{F_{t}}{2 \pi \rho^{2}} g_{i j}(\phi, \theta)_{v} .
$$

In addition to the influence of scratching force on the formation of the elastic stress field, the residual stress generated by the plastic deformation area after scratching would also affect the formation of elastic stress field, which is blister field stress field proposed by Yoffe [19]. 


$$
\left\{\begin{array}{c}
\gamma_{R R}=\frac{4 B}{R^{3}}\left[(5-v) \cos ^{2} \phi-(2-v)\right] \\
\gamma_{\phi \phi}=-\frac{B}{R^{3}} 2(1-2 v) \cos ^{2} \phi \\
\gamma_{X X}=\frac{B}{R^{3}} 2(1-2 v)\left(2-3 \cos ^{2} \phi\right) \\
\gamma_{R \phi}=\frac{B}{R^{3}} 4(1+v) \sin \phi \cos \phi \\
\gamma_{R X}=0 \\
\gamma_{x \phi}=0
\end{array} .\right.
$$

Where $v$ is the Poisson's ratio, $B=0.026 f E\left(\mathrm{~F}_{n} / \mathrm{H}\right)^{3 / 2}$ is the blister stress strength [22], and $f$ is the compaction coefficient. The model can be written as a general formula by

$$
\gamma_{i j}=\frac{B}{R^{3}} h_{i j}(\phi, \theta)_{v} \text {. }
$$

The scratch elastic stress field of single grain scratching is obtained by superposition of formula (1) and formula (3). Its general formula is

$$
\sigma_{i j}=\frac{F_{n}}{2 \pi \rho^{2}} f_{i j}(\phi, \theta)_{v}+\frac{F_{t}}{2 \pi \rho^{2}} g_{i j}(\phi, \theta)_{v}+\frac{B}{\rho^{3}} h_{i j}(\phi, \theta)_{v} .
$$

It can be concluded from the formula (5) that the stress field intensity decreases with the increase of $\rho$ in the process of single grain scratching. Therefore, stress concentration is most likely to occur in the elastic-plastic deformation boundary $(\rho=b)$, leading to the generation and propagation of cracks. According to fracture mechanics, the principal stress affects the generation and propagation of cracks. The principal stress calculation formula is given by

$$
\left\{\begin{array}{l}
\sigma_{11}=\frac{\sigma_{\mathrm{rr}}+\sigma_{z z}}{2}+\sqrt{\left(\frac{\sigma_{\mathrm{rr}}-\sigma_{z z}}{2}\right)^{2}+\sigma_{r z}{ }^{2}} \\
\sigma_{22}=\sigma_{\theta \theta} \\
\sigma_{33}=\frac{\sigma_{\mathrm{rr}}+\sigma_{z z}}{2}-\sqrt{\left(\frac{\sigma_{\mathrm{rr}}-\sigma_{z z}}{2}\right)^{2}+\sigma_{r z}{ }^{2}}
\end{array} .\right.
$$

\section{SPH simulation model of single grain scratching}

\subsection{SPH method theory}

The SPH method, first proposed by Gingold and Monaghan in 1977, is to discrete a continuous object into a series of movable particles which carry the physical properties of the original object [31]. The core of SPH method is the interpolation algorithm. The interpolation function is used to represent the interaction between the particles, which constitutes Lagrange algorithm. Each particle has a core estimate in the quantity field described by the interpolation function. By converting the conservation law of continuous medium dynamics from the differential form to the integral 
form [32-34], the dynamic behavior of the whole system is obtained. The approximate kernel function of a particle is

$$
\Pi^{h} f\left(\mathrm{r}_{0}\right)=\int f(\mathrm{r}) \mathrm{W}\left(\mathrm{r}_{0}-\mathrm{r}, \mathrm{h}\right) \mathrm{dr} .
$$

Where $W$ is a smooth function (or kernel function), as shown in Fig. $2, h$ is the smooth length, $f$ is a function of the three-dimensional coordinate vector $r, r_{0}$ is the position vector of the arbitrary point, and $r$ is the position vector of the approximate calculated point.

The most commonly used smooth kernel function is the smooth function of the cubic B-spline [35-36], which is defined as follows

$$
\mathrm{W}\left(\mathrm{r}_{0}-\mathrm{r}, \mathrm{h}\right)=\mathrm{W}(\mathrm{R}, \mathrm{h})=a_{d}\left\{\begin{array}{l}
\frac{2}{3}-R^{2}+\frac{1}{2} R^{3}, 0 \leq R<1 \\
\frac{1}{6}(2-\mathrm{R})^{3}, 1 \leq R<2 \\
0, R \geq 2
\end{array} .\right.
$$

Where $a_{d}=\frac{3}{2 \pi h^{3}}$ is a constant of normalization in three-dimensional space.

\subsection{SPH geometric model}

The SPH simulation model of single grain scratching is shown in Fig. 3. In this model, the density of diamond grain is $3.52 \mathrm{~g} \cdot \mathrm{cm}^{-3}$, the modulus of elasticity is $1140 \mathrm{GPa}$, and Poisson's ratio is 0.07 . The diamond grain is simplified to an ideal rigid body and modeled by a finite element mesh method. Its movement direction is horizontal (X direction). The optical quartz glass is modeled by SPH method, its size is $70 \mu \mathrm{m} \times 30 \mu \mathrm{m} \times 35 \mu \mathrm{m}$, and the total number of particles is 588,000. All degrees of freedom of SPH particles at the bottom and right of the simulation model are constrained to prevent the workpiece movement during the scratching. In the simulation, the grain and workpiece are contacted through "*Contact_eroding_nodes_to_surface", whose mechanical parameters are transferred by penalty function. The "*Contact_eroding_nodes_to_surface" in the LSDYNA software is an asymmetric contact method with excellent computational efficiency and can be used for the processing with material damage.

\subsection{JH-2 material model}

The JH-2 material model [37] is adopted in the simulation of optical quartz glass, which is widely applied to hard-brittle materials such as glass and ceramics. It mainly describes the strength, pressure and damage of the material, including the internal damage accumulation of the material. In addition, it possesses good effect, according to the specific parameters in Table 1 [38]. In this model, the equivalent stress can be expressed as follows 


$$
\sigma^{*}=\sigma_{i}^{*}-D\left(\sigma_{i}^{*}-\sigma_{f}^{*}\right)
$$

Where $\sigma_{i}^{*}$ is the complete strength and $\sigma_{f}^{*}$ is breaking strength, $D$ is the damage variable $(0 \leq D \leq 1)$ whose expression is

$$
D=\sum \frac{\Delta \varepsilon^{p}}{\varepsilon_{f}^{p}} .
$$

Where, $\Delta \varepsilon^{p}$ is the strain increment and $\varepsilon_{f}^{p}$ is the strain when plastic fracture occurs.

\section{Simulation results and discussion}

\subsection{Subsurface Crack generation and propagation}

Fig. 4 shows the single grain scratching process at the scratching speed of $45 \mathrm{~m} / \mathrm{s}$ and different scratching depths. Only plastic deformation occurs and no obvious crack exists on the subsurface when the scratching depth is $1 \mu \mathrm{m}$, which indicates that the material is removed in ductile mode. When the scratching depth is $1.5 \mu \mathrm{m}$, an obvious extended plastic strain band appears under the surface, which indicates the initiation of crack [26, 34]. Then, brittle removal occurs in the process of material removal. When the scratching depth is $3 \mu \mathrm{m}$ or $4.5 \mu \mathrm{m}$, it can be seen that deep median cracks exist on the subsurface, generating complicated material deformation. And the material removal mode is brittle fracture. The simulation presents that ductile removal mode occurs when the scratching depth is less than $1 \mu \mathrm{m}$, which is basically consistent with the experiment results obtained by Zhao et al. [39].

In order to better analyze the crack generation and propagation, this paper only studies the principal tensile stress that causes crack opening [40]. According to the formula (6) constructed by scratch elastic stress field model, the normalized distribution of the principal stress $\sigma_{i i} \pi b^{2} / F_{n}$ at the elastic-plastic boundary $(\rho=b)$ is shown in Fig. 5. It can be seen that in the plane of $\theta=0$, the maximum and second principal stresses reach the maximum value near the location $\phi=28^{\circ}$. Due to the influence of tensile stress concentration, the crack would generate near this location when the stress exceeds the material fracture stress.

Fig. 6 shows the cracks generation and propagation at the scratching depth of $3 \mu \mathrm{m}$ and scratching speed of $45 \mathrm{~m} / \mathrm{s}$. As presented in Fig. $6 \mathrm{a}(\mathrm{t}=0.65 \mu \mathrm{s})$, crack generate at the location $\phi=26^{\circ}$ in front the grain, consistent with the above theoretical analysis. The crack then propagates along this direction with the grain movement, similar to the loading stage in the indentation experiment. Besides, as shown in Fig. 6b, cracks could be formed in the peak deformation zone [41]. When $\mathrm{t}=0.9 \mu$ s (Fig. 6c), the grain just moves over the crack and is about to leave in the unloading stage, and the 
crack begins to propagate downward. When $\mathrm{t}=1.15 \mu$ s (Fig. $6 \mathrm{~d}$ ), the grain is completely unloaded after scratching, while the crack which propagates downward closes to form a median crack, causing the subsurface damage. As presented in Fig. $6 \mathrm{e}(\mathrm{t}=0.9 \mu \mathrm{s})$, when the grain is about to unload, elastic recovery occurs and the lateral crack parallel to the surface generates on the subsurface. In the following scratching process, the lateral cracks gradually expand to the free surface, resulting in the brittle removal of material, as shown in Fig. $6 \mathrm{f}-6 \mathrm{~h}(\mathrm{t}=0.95 \sim 1.05 \mu \mathrm{s})$. Some microcracks remain in the elastic-plastic boundary after the grain is completely unloaded, as shown in Fig. $6 \mathrm{~h}$.

\subsection{Subsurface crack depth and plastic deformation depth}

Fig. 7 shows the depth of maximum subsurface crack and plastic deformation on the subsurface at the scratching speed of $45 \mathrm{~m} / \mathrm{s}$ and different scratching depths. The Fig. 7 indicates that when the scratching depth is less than $1 \mu \mathrm{m}$, no crack exists on the subsurface. When the scratching depth is $1.5 \mu \mathrm{m}$, the maximum subsurface crack depth is $6.5 \mu \mathrm{m}$. However, when the scratching depth is $4.5 \mu \mathrm{m}$, the maximum subsurface crack depth reaches $14 \mu \mathrm{m}$. The results show that with the increase of scratching depth, the material removal mode changes from plastic deformation to brittle fracture, which leads to the rise of the depth of subsurface crack.

In addition, Fig. 7 also demonstrates that the plastic deformation depth increases in accordance with the rising the scratching depth. That is because the material with plastic deformation will be generated by strong pressing action which correspondingly is derived from large contact area and scratching depth. As optical quartz glass has high silica content, it would also undergo significant material densification when it is pressed [42]. The densification is due to the formation of over-coordination between silicon atoms under pressure, and then the dense accumulation of atoms [43], contributing to the increase of local atomic density. It would bring about irreversible damage to the material and affect the transparency of optical quartz glass. The results show that with the increase of scratching depth, larger pressure on the material will generate greater densification degree.

\subsection{The effect of scratching speed on subsurface crack}

The subsurface crack propagation and distribution at the scratching depth of $3 \mu \mathrm{m}$ and different scratching speeds are shown in Fig. 8. When the scratching speed is $15 \mathrm{~m} / \mathrm{s}$, many median cracks take shape on the subsurface. The maximum median crack depth is $13 \mu \mathrm{m}$, indicating the serious brittle fracture on the material during scratching. When the scratching speed is $30 \mathrm{~m} / \mathrm{s}$, the maximum median crack depth decreases to $11 \mu \mathrm{m}$, and correspondingly the plastic 
deformation degree decreases. When the scratching speed is $45 \mathrm{~m} / \mathrm{s}$, the maximum median crack depth increases slightly. The maximum median crack depth is further reduced when the scratching speed is 60 and $75 \mathrm{~m} / \mathrm{s}$, and other subsurface crack depths are also decreased. When the scratching speed is $90 \mathrm{~m} / \mathrm{s}$, the maximum median crack depth reduces to 7.5 $\mu \mathrm{m}$, which is $42 \%$ lower than that of $15 \mathrm{~m} / \mathrm{s}$, and the number of subsurface cracks reduces significantly.

The above analysis indicates that with the increasing scratching speed, both the maximum depth of subsurface cracks and the number of subsurface cracks decrease. That is because the material strain rate increases at a higher scratching speed, thus leading to the increase of the material dynamic fracture toughness [44] and inhibiting the crack generation and propagation. Scinker et al. [45] pointed out that when the cutting speed exceeds a certain limit, the glass can be removed in the ductile mode. Therefore, increasing the grinding speed is conducive to reducing the subsurface damage and improving the machining quality of optical quartz glass, which provides a theoretical basis for the suppression of subsurface damage in grinding.

\subsection{Scratching force}

Fig. 9a shows the tangential scratching force at different scratching depths with the speed of $45 \mathrm{~m} / \mathrm{s}$. When the scratching depth is $1 \mu \mathrm{m}$, the scratching force rarely fluctuates and remains under a relatively stable state, due to the ductile mode for material removal. When the scratching depth is $1.5 \mu \mathrm{m}$, brittle removal occurs and then the scratching force begins to fluctuate. When the scratching depths are 3 and $4.5 \mu \mathrm{m}$, the scratching force fluctuates greatly, as the material removal is completely in the brittle mode. The average scratching force and the force fluctuation degree increase with rising scratching depth, as shown in Fig. 9b. The reason for complicated deformation is that with the increasing scratching depth, the amount of material removed and the maximum undeformed chip thickness correspondingly increase, making the force needed to overcome material deformation and friction on the rise.

Fig. 10 shows the average scratching force in steady stage at the scratching depth of $3 \mu \mathrm{m}$ and different scratching speed. With the increase of scratching speed, the normal force and tangential force decrease, and the degree of force fluctuation decreases accordingly. That is because the maximum undeformed chip thickness decreases when speed accelerates [46], along with the decreasing friction between the grain and the material decreases and the scratching force. It is conducive to promoting the ductile machining of optical quartz glass. 
According to formula (5), when the scratching force grows larger, the scratch elastic stress in the scratching process would increase. It explains that the material is easy to be in brittle machining mode at low grinding speed or high grinding depth. Therefore, in order to avoid serious subsurface damage in the grinding process, a smaller grinding depth or a larger grinding speed should be selected.

\subsection{Subsurface residual stress}

Residual stress is a kind of stress remaining inside the material to maintain its own balance due to uneven deformation after machining [47-49]. Although the residual stress has no direct effect on the crack generation, it would affect the propagation of the existing crack, thus influencing the optical properties of the material. Therefore, as another kind of subsurface damage, the subsurface residual stress also needs to be suppressed during machining.

The distribution of subsurface residual stress under the scratching depth of $3 \mu \mathrm{m}$ and scratching speed of $45 \mathrm{~m} / \mathrm{s}$ is shown in Fig. 11a. Fig. 11a presents that the residual stress exists widely on the subsurface, which would promote microcracks to grow and exert a profound impact on the material performance. The maximum depth of the residual stress is $14 \mu \mathrm{m}$ and its cross-section is shown in B-B. As shown in Fig. 11b, the distribution of residual stress on cross section B-B is consistent with the normalized distribution of the maximum principal stress $\sigma_{11} \pi b^{2} / F_{n}$ derived from the formula (6). It can be seen from Fig. 11a that the residual stress is concentrated at the bottom of the scratch, and the residual stress value is the largest. Residual stress also exists on both sides of the scratch and decreases as the depth reduces. However, the residual stress near the upper surface increases slightly, which would cause the nucleation of the Hertz crack and then affect the surface quality.

The residual stress depth of subsurface at different scratching depth and speed is shown in Fig. 12. Fig. 12 shows that with the increase of scratching depth or the decrease of scratching speed, the subsurface residual stress depth increases. That is because the maximum undeformed chip thickness and the scratching force increase, resulting in complex material deformation and large depth of residual stress. When the scratching depth is less than $1.5 \mu \mathrm{m}$ or the scratching speed is greater than $75 \mathrm{~m} / \mathrm{s}$, the residual stress value and the depth of residual stress are relatively small, thus the subsurface damage is small. The comprehensive analysis shows that a smaller grinding depth or a larger grinding speed should be selected in order to effectively restrain the subsurface residual stress.

\section{Scratching experiment}




\subsection{Experiment setup}

The optical quartz glass sample is $25 \mathrm{~mm} \times 25 \mathrm{~mm} \times 5 \mathrm{~mm}$ in terms of the size, and it was prepared by double-side polishing to obtain good surface quality and flatness on both sides. The average surface roughness $\mathrm{R}_{\mathrm{a}}$ measured by the Zygo white light interferometer is $1.002 \mathrm{~nm}$, which is in line with the basic requirements of the experiment. The scratching experiment was carried out on a three-axis ultra-precision diamond turning machine (Fig. 13a), the precision of the machine reached $0.1 \mu \mathrm{m}$, fully meeting the requirements of experimental precision. The tool used in the experiment is a diamond indenter with a cone angle of $120^{\circ}$ and a edge radius of $10 \mu \mathrm{m}$, the specific geometric parameters are shown in Fig. 13b. Kistler dynamometer instrument records the force during the scratching in real time, and the displacement sensor records the displacement of the indenter. The schematic diagram of variable depths scratching is shown in Fig. 13c. The scratching speed is $0.1 \mathrm{~m} / \mathrm{s}$ and the scratching length is $1000 \mu \mathrm{m}$.

\subsection{Experimental results and discussion}

The overall scratch morphology of the optical quartz glass was measured by the laser confocal microscope, as shown in Fig. 14a. When the scratching depth is small, the optical quartz glass is only plastically deformed and no cracks are generated. As shown in Fig. 14b, the lateral crack gradually expands upward and takes shape on the scratch surface while the median crack is formed. When the scratching depth increases further, large lateral cracks will appear, as shown in Fig. 14c. In the stable scratching stage, the Hertz crack takes shape on the surface and interacts with the lateral crack, resulting in brittle removal of the material, as shown in Fig. 14d. As shown in Fig. 14e, at the end of the scratch, the number of Hertz cracks increases and the lateral cracks are cut into small pieces, leading to the microfracture removal of the material and leaving a large number of microcracks on the surface. The generation and propagation of cracks in scratching experiment are consistent with the simulation analysis and are similar to the experimental results of Wang et al. [50].

Fig. 15 shows how the scratching force and the scratching depth are related in the experiment. It can be seen from Fig. 15 that the scratching force increases with rising scratching depth and fluctuates in the scratching process. The experimental and simulation scratching force have the same variation tendency, which verifies the correctness of the simulation analysis.

\section{Conclusion}


In this paper, the single grain scratching SPH simulation model of optical quartz glass was established to study the subsurface damage of optical quartz glass combined with the scratch elastic stress field model. To verify the SPH simulation model, the scratching experiment of optical quartz glass was carried out to investigate the generation and propagation of the cracks. The comparison between the experiment results and the simulation results had verified correctness of the simulation analysis.

Simulation and theoretical analysis show that the cracks generate firstly at the elastic-plastic deformation boundary $(\rho=b)$ in front of the grain $\left(\phi=28^{\circ}\right)$ due to the influence of the maximum principal tensile stress. The median crack is closed to form the subsurface damage, while the lateral crack propagates to the free surface to promote the brittle removal of material, and microcracks remain at the elastic-plastic boundary. According to the analysis of subsurface crack depth, scratching force, and subsurface residual stress, it is found that a smaller grinding depth or a larger grinding speed is conducive to reducing the subsurface damage and improving the machining quality of optical quartz glass.

\section{Acknowledgments}

The authors would like to acknowledge the financial support from the National Natural Science foundation of China (General Program) (NO. 51575083), Science Fund for Creative Research Groups (NO. 51621064), and the EPSRC(EP/K018345/1 and EP/T024844/1) in the UK.

\section{Data Statement}

All data underpinning this publication are openly available from the University of Strathclyde Knowledge Base.

\section{Reference}

[1] M. Joodaki, G. Kompa, Application of neural networks for extraction of distance and reflectance in pulsed laser radar, Measurement 40 (6) (2007) 724-736.

[2] P. Neumayer, H.J. Lee, D. Offerman, E. Shipton, A. Kemp, A.L. Kritcher, T. Döppner, C.A. Back, S.H. Glenzer, Isochoric heating of reduced mass targets by ultra-intense laser produced relativistic electrons, High Energy Density Phys. 5 (4) (2009) 244-248.

[3] H.T. Liu, Y.Z. Sun, C.X. Zhang, Experimental research of brittle-ductile transition conditions and tool wear for micromilling of glass material, Int. J. Adv. Manuf. Technol. 68 (5-8) (2013) 1901-1909.

[4] C.D. Marshall, J.A. Speth, S.A. Payne, Induced optical absorption in gamma, neutron and ultraviolet irradiated fused quartz and silica, 
J. Non-Cryst. Solids. 212 (1) (1997) 59-73.

[5] S. Yin, S. Morita, H. Ohmori, Y. Uehara, W. Lin, Q. Liu, T. Maihara, F. Iwamuro, D. Mochida, ELID precision grinding of large special Schmidt plate for fibre multi-object spectrograph for $8.2 \mathrm{~m}$ Subaru telescope, Int. J. Mach. Tools Manuf. 45 (14) (2005) $1598-1604$.

[6] J. Chen, Q. Fang, P. Li, Effect of grinding wheel spindle vibration on surface roughness and subsurface damage in brittle material grinding, Int. J. Mach. Tools Manuf. 91 (2015) 12-23.

[7] W.K. Neo, A.S. Kumar, M. Rahman, A review on the current research trends in ductile regime machining, Int. J. Adv. Manuf. Technol. $63(5-8)(2012) 465-480$

[8] M. Arif, M. Rahman, W.Y. San, Analytical model to determine the critical conditions for the modes of material removal in the milling process of brittle material, J. Mater. Process. Technol. 212 (9) (2012) 1925-1933.

[9] W. Gu, Z. Yao, H. Li, Investigation of grinding modes in horizontal surface grinding of optical glass BK7, J. Mater. Process. Technol. $211(10)(2011) 1629-1636$.

[10] P. Bandyopadhyay, A. Dey, A.K. Mandal, N. Dey, A.K. Mukhopadhyay, New observations on scratch deformations of soda lime silica glass, J. Non-Cryst. Solids. 358 (16) (2012) 1897-1907.

[11] X.H. Lin, J.B. Zhang, H.H. Tang, X.Y. Du, Y.B. Guo, Analysis of surface errors and subsurface damage in flexible grinding of optical fused silica, Int. J. Adv. Manuf. Technol. 88 (1-4) (2017) 643-649.

[12] S. Gao, Z. Geng, Y. Wu, Z. Wang, R. Kang, Surface integrity of quartz glass induced by ultra-precision grinding, J. Mech. Eng. 55 (5) (2019) 186-195.

[13] P.W. Bridgman, I. Šimon, Effects of very high pressures on glass, J. Appl. Phys. 24 (4) (1953) 405-413.

[14] T.G. Bifano, T.A. Dow, R.O. Scattergood, Ductile-regime grinding: a new technology for machining brittle materials, J. Eng. Ind. 113 (1991) 184-189.

[15] A. Muhammad, X. Zhang, R. Mustafizur, K. Senthil, A predictive model of the critical undeformed chip thickness for ductile-brittle transition in nano-machining of brittle materials, Int. J. Mach. Tools Manuf. 64 (4) (2013) 114-122.

[16] B. Guo, Q. Zhao, Wheel normal grinding of hard and brittle materials, Int. J. Adv. Manuf. Technol. 79 (5-8) (2015) 873-880.

[17] K. Li, T.W. Liao, Surface/subsurface damage and the fracture strength of ground ceramics, J. Mater. Process. Technol. 57 (3-4) (1996) 207-220. 
[18] K.L. Johnson, The correlation of indentation experiments, J. Mech. Phys. Solids. 18 (2) (1970) 115-126.

[19] E.H. Yoffe, Elastic stress fields caused by indenting brittle materials, Philos. Mag. A. 46 (4) (1982) 617-628.

[20] Y. Ahn, T.N. Farris, S. Chandrasekar, Sliding microindentation fracture of brittle materials: Role of elastic stress fields, Mech. Mater. $29(3-4)(1998) 143-152$.

[21] L. Cai, X. Guo, S. Gao, Z. Li, R. Kang. Material removal mechanism and deformation characteristics of AlN ceramics under nanoscratching, Ceram. Int. 45 (16) (2019) 20545-20554.

[22] R.F. Cook, G.M. Pharr, Direct observation and analysis of indentation cracking in glasses and ceramics, J. Am. Ceram. Soc. 73 (4) (1990) 787-817.

[23] X.N. Jing, S. Maiti, G. Subhash, A new analytical model for estimation of scratch-induced damage in brittle solids, J. Am. Ceram. Soc. 90 (3) (2007) 885-892.

[24] A. Mir, X.C. Luo, J.N. Sun, The investigation of influence of tool wear on ductile to brittle transition in single point diamond turning of silicon, Wear. 364-365 (2016) 233-243.

[25] J. Lai, H. Wang, H. Yang, X. Zheng, Q. Wang, Dynamic properties and SPH simulation of functionally graded cementitious composite subjected to repeated penetration, Constr. Build. Mater. 146 (2017) 54-65.

[26] Y. Liu, B. Li, C. Wu, L. Kong, Y. Zheng, Smoothed particle hydrodynamics simulation and experimental analysis of SiC ceramic grinding mechanism, Ceram. Int. 44 (11) (2018) 12194-12203.

[27] W. Gu, Z. Yao, Evaluation of surface cracking in micron and sub-micron scale scratch tests for optical glass BK7, J. Mech. Sci. Technol. 25 (5) (2011) 1167.

[28] Z. Yao, W. Gu, K. Li, Relationship between surface roughness and subsurface crack depth during grinding of optical glass BK7, J. Mater. Process. Technol. 212 (4) (2012) 969-976.

[29] C. Wu, B. Li, Y. Liu, S.Y. Liang, Surface roughness modeling for grinding of silicon carbide ceramics considering co-existence of brittleness and ductility, Int. J. Mech. Sci. 133 (2017) 167-177.

[30] H.T. Zhu, C.Z. Huang, J. Wang, Q.L. Li, C.L. Che, Experimental study on abrasive waterjet polishing for hard-brittle materials, Int. J. Mach. Tools Manuf. 49 (7-8) (2009) 569-578.

[31] R.A. Gingold, J.J. Monaghan, Smoothed particle hydrodynamics: theory and application to non-spherical stars, Mon. Not. Roy. Astron. Soc. 181 (3) (1977) 375-389. 
[32] J. Cao, Y. Wu, J. Li, Q. Zhang, Study on the material removal process in ultrasonic-assisted grinding of SiC ceramics using smooth particle hydrodynamic (SPH) method, Int. J. Adv. Manuf. Technol. 83 (5-8) (2016) 985-994.

[33] A. Mir, X. Luo, K. Cheng, A. Cox, Investigation of influence of tool rake angle in single point diamond turning of silicon, Int. J. Adv. Manuf. Technol. 94 (5-8) (2018) 2343-2355.

[34] X. Guo, Y. Shi, X. Luo, R. Kang, Z. Jin, F. Ding, Z. Li, Mechanism of crack propagation for K9 glass, Int. J. Precis. Eng. Manuf. 20 (5) (2019) 815-825.

[35] J. Limido, C. Espinosa, M. Salaün, J.L. Lacome, SPH method applied to high speed cutting modelling, Int. J. Mech. Sci. 49 (7) (2007) 898-908.

[36] M.R.I. Islam, C. Peng, A Total Lagrangian SPH method for modelling damage and failure in solids, Int. J. Mech. Sci. 157 (2019) 498-511.

[37] G.R. Johnson, T.J. Holmquist, An improved computational constitutive model for brittle materials, AIP Conf. Proc. 309 (1) (1994) 981-984.

[38] D.S. Cronin, K. Bui, C. Kaufmann, G. Mclntosh, T. Berstad, Implementation and validation of the Johnson-Holmquist ceramic material model in LS-Dyna, Proc. 4th Eur. LS-DYNA Users Conf. 1 (2003) 47-60.

[39] Q.L. Zhao, D. Stephenson, J. Corbett, J. Hedge, J.H. Wang, Y.C. Liang, Single grit diamond grinding of spectrosil 2000 glass on tetraform 'C', Key Eng. Mater. 257 (2004) 107-112.

[40] M.V. Swain, Microfracture about scratches in brittle solids, Proc. R. Soc. A-Math. Phys. Sci. 366 (1727) (1979) 575-597.

[41] M.B. Cai, X.P. Li, M. Rahman, A.A.O. Tay, Crack initiation in relation to the tool edge radius and cutting conditions in nanoscale cutting of silicon, Int. J. Mach. Tools Manuf. 47 (3-4) (2007) 562-569.

[42] C. Hermansen, J. Matsuoka, S. Yoshida, H. Yamazaki, Y. Kato, Y.Z. Yue, Densification and plastic deformation under microindentation in silicate glasses and the relation to hardness and crack resistance, J. Non-Cryst. Solids, 364 (2013) 40-43.

[43] K. Nomura, Y.C. Chen, R.K. Kalia, A. Nakano, P. Vashishta, Defect migration and recombination in nanoindentation of silica glass, Appl. Phys. Lett. 99 (11) (2011) 111906.

[44] Y. Liu, B. Li, C. Wu, Y. Zheng, Simulation-based evaluation of surface micro-cracks and fracture toughness in high-speed grinding of silicon carbide ceramics, Int. J. Adv. Manuf. Technol. 86 (1-4) (2016) 799-808. 
[46] S. Agarwal, P.V. Rao, Experimental investigation of surface/subsurface damage formation and material removal mechanisms in SiC grinding, Int. J. Mach. Tools Manuf. 48 (6) (2008) 698-710.

[47] J. Chen, Q. Fang, L. Zhang, Investigate on distribution and scatter of surface residual stress in ultra-high speed grinding, Int. J. Adv. Manuf. Technol. 75 (1-4) (2014) 615-627.

[48] T. Horn, C. Silbermann, J. Ihlemann, FE-Simulation based analysis of residual stresses and strain localizations in ECAP processing, PAMM. 17 (1) (2017) 309-310.

[49] D. Wu, H. Jing, L. Xu, L. Zhao, Y. Han, Analytical approaches of creep crack initiation prediction coupled with the residual stress and constraint effect, Eur. J. Mech. A-Solids. 71 (2018) 1-15.

[50] W. Wang, P. Yao, J. Wang, C. Huang, T. Kuriyagawa, H. Zhu, B. Zou, H. Liu, Elastic stress field model and micro-crack evolution for isotropic brittle materials during single grit scratching, Ceram. Int. 43 (14) (2017) 10726-10736.

\section{Figures and Table:}

Fig. 1. Diagram of single grain scratching in the cylindrical coordinate system $(r, z, \theta)$.

Fig. 2. SPH smooth kernel function.

Fig. 3. SPH model of single grain scratching.

Fig. 4. Distribution of plastic deformation at the scratching speed of $45 \mathrm{~m} / \mathrm{s}$ and scratching depth of (a) $1 \mu \mathrm{m}$, (b) $1.5 \mu \mathrm{m}$, (c) $3 \mu \mathrm{m}$ and (d) $4.5 \mu \mathrm{m}$.

Fig. 5. Normalized distribution of the principal stress $\sigma_{i i} \pi b^{2} / F_{n}$ in the plane of $\theta=0$ (plane of XOY).

Fig. 6. Generation and propagation of cracks at $3 \mu \mathrm{m}$ scratching depth and $45 \mathrm{~m} / \mathrm{s}$ scratching speed, a-d are viewed along the direction perpendicular to the scratching, and e-h viewed along the scratching direction.

Fig. 7. Maximum depth of subsurface crack and plastic deformation at different scratching depths.

Fig. 8. Subsurface crack propagation and distribution at $3 \mu \mathrm{m}$ scratching depth and scratching speed of (a) $15 \mathrm{~m} / \mathrm{s}$, (b) $30 \mathrm{~m} / \mathrm{s}$, (c) $45 \mathrm{~m} / \mathrm{s}$, (d) $60 \mathrm{~m} / \mathrm{s}$, (e) $75 \mathrm{~m} / \mathrm{s}$ and (f) $90 \mathrm{~m} / \mathrm{s}$.

Fig. 9. Tangential force (a) and average scratching force (b) at scratching depth of $1 \mu \mathrm{m}, 1.5 \mu \mathrm{m}, 3 \mu \mathrm{m}$ and $4.5 \mu \mathrm{m}$.

Fig. 10. Average scratching force at the scratching depth of $3 \mu \mathrm{m}$ and different scratching speeds (from $15 \mathrm{~m} / \mathrm{s}$ to $90 \mathrm{~m} / \mathrm{s}$ ).

Fig. 11. (a) Distribution of subsurface residual stress at the scratching depth of $3 \mu \mathrm{m}$ and scratching speed of $45 \mathrm{~m} / \mathrm{s}$, (b) Normalized distribution of maximum principal stress $\sigma_{11} \pi b^{2} / F_{n}$ on section B-B. 
Fig. 12. Subsurface residual stress depth at (a) different scratching depths and (b) different scratching speeds.

Fig. 13. (a) Scratching experiment equipment, (b) geometric parameters of indenter and (c) scratching schematic diagram.

Fig. 14. Scratch morphology of optical quartz glass, (a) overall scratch morphology, (b) median and lateral crack generation, (c) median and lateral crack propagation, (d) Hertz crack generation and (e) microcrack generation.

Fig. 15. Experimental scratching force at different scratching depths.

Table 1 Material model parameters of optical quartz glass.

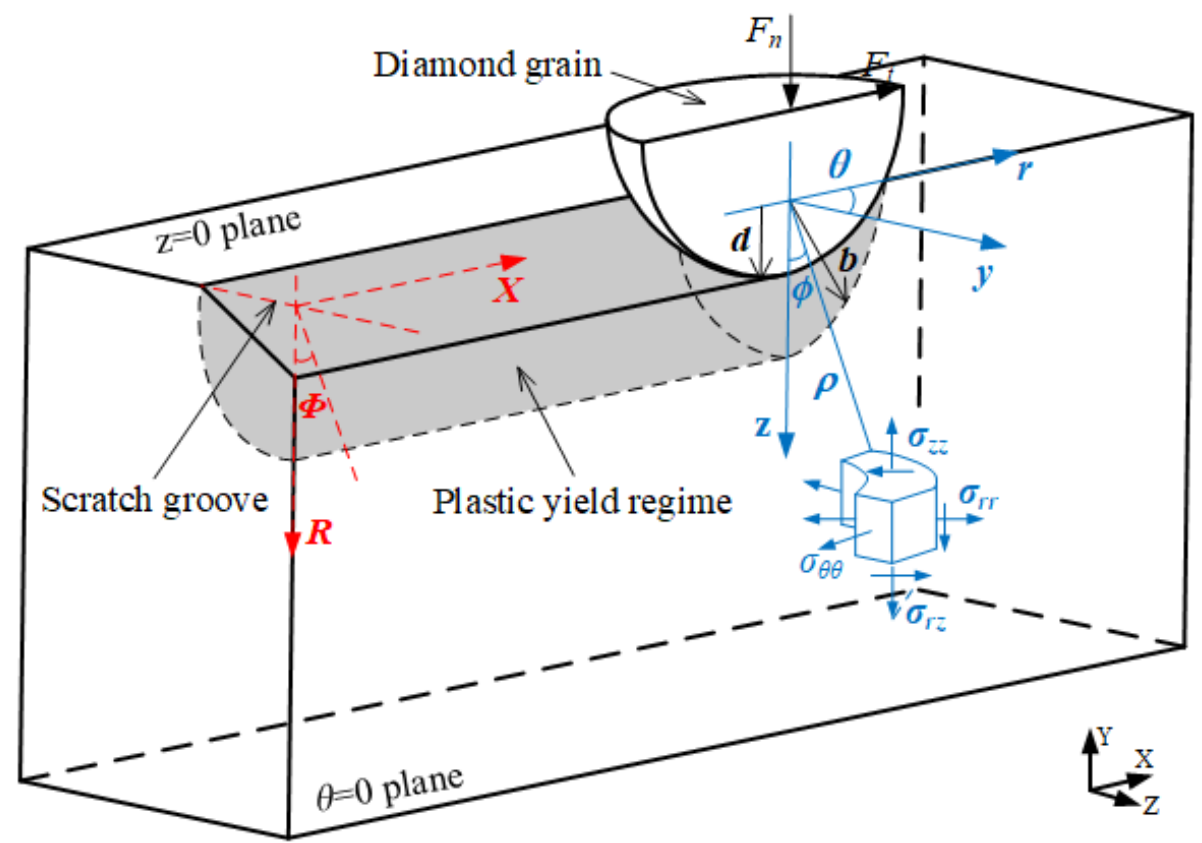

Fig. 1

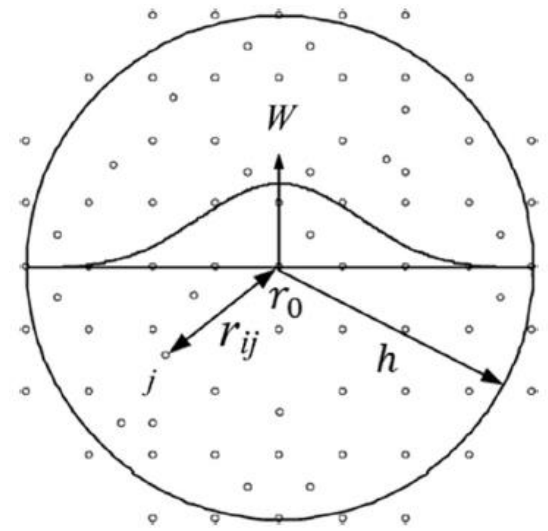

Fig. 2 


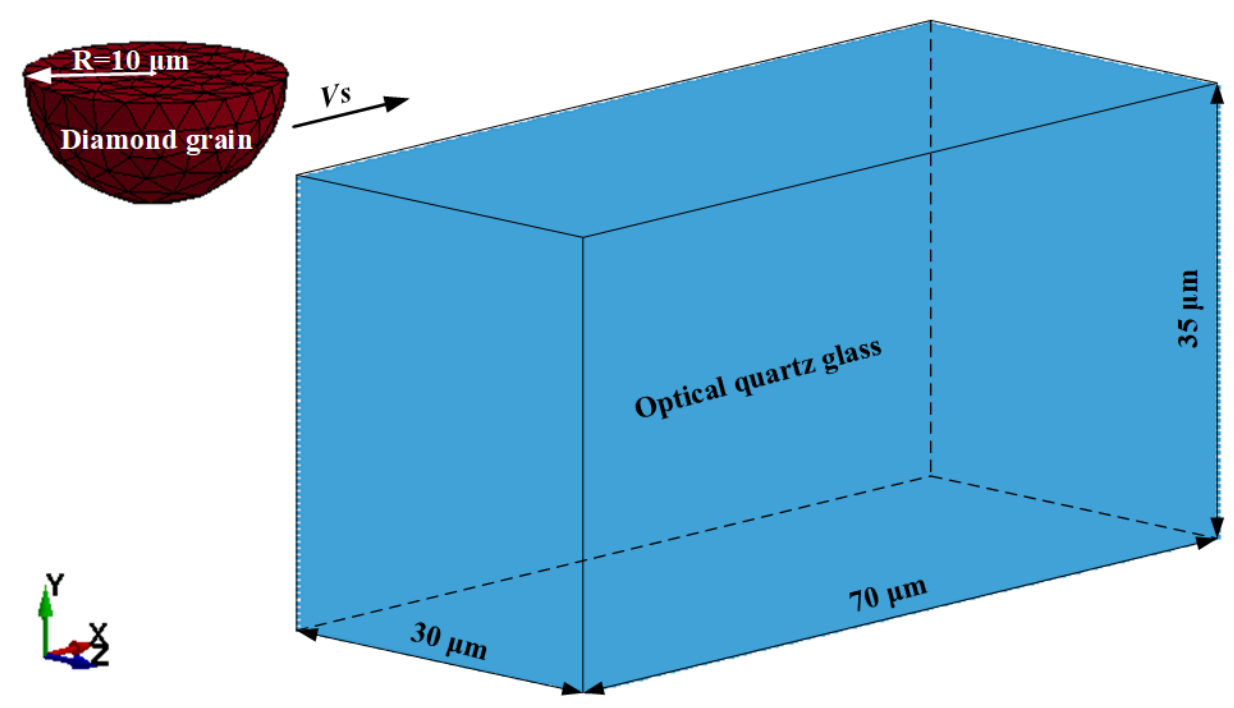

Fig. 3
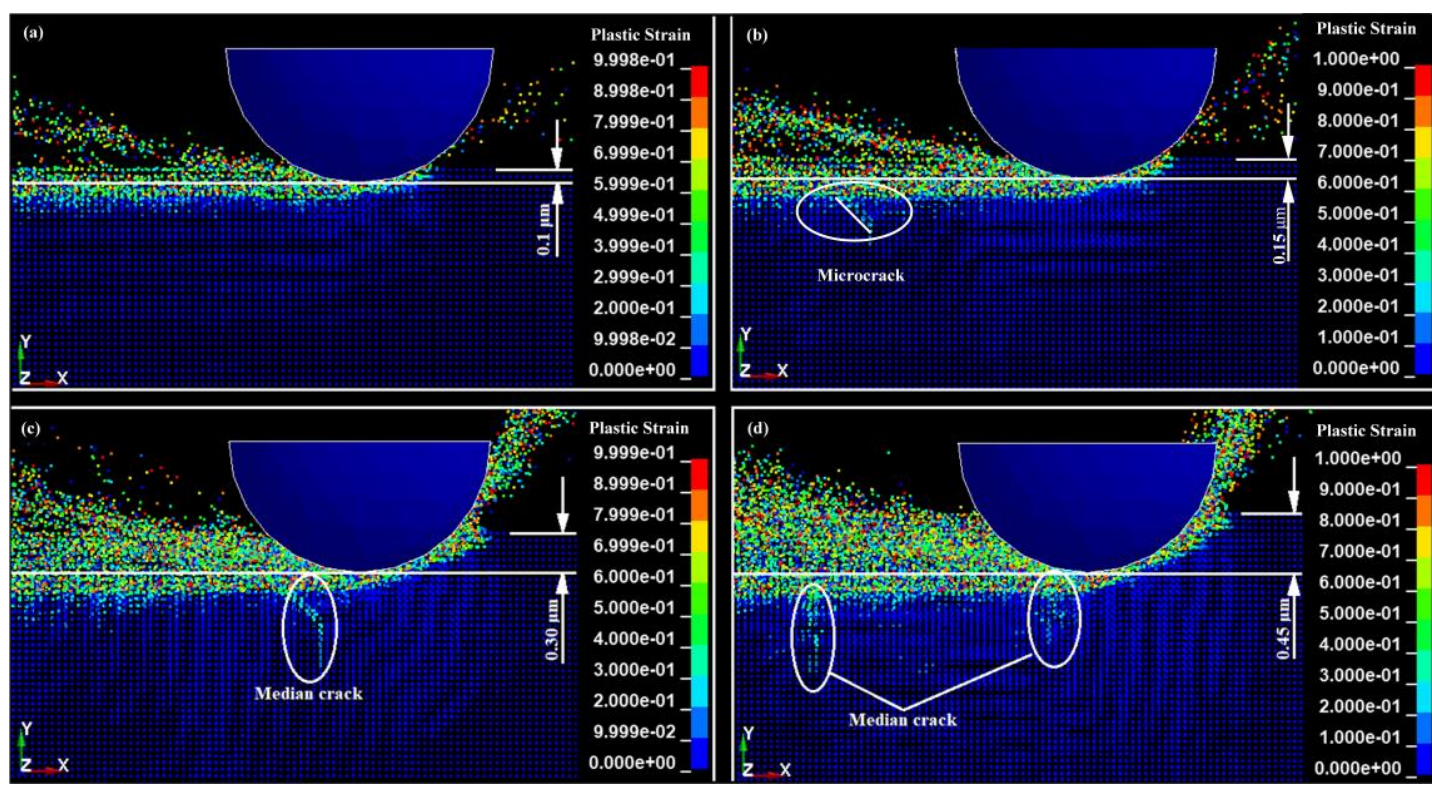

Fig. 4

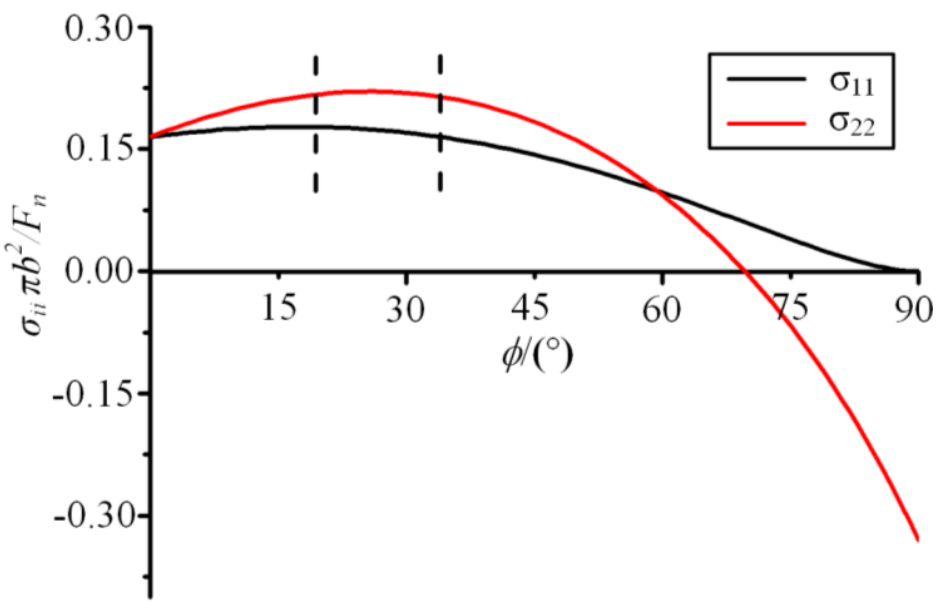

Fig. 5 


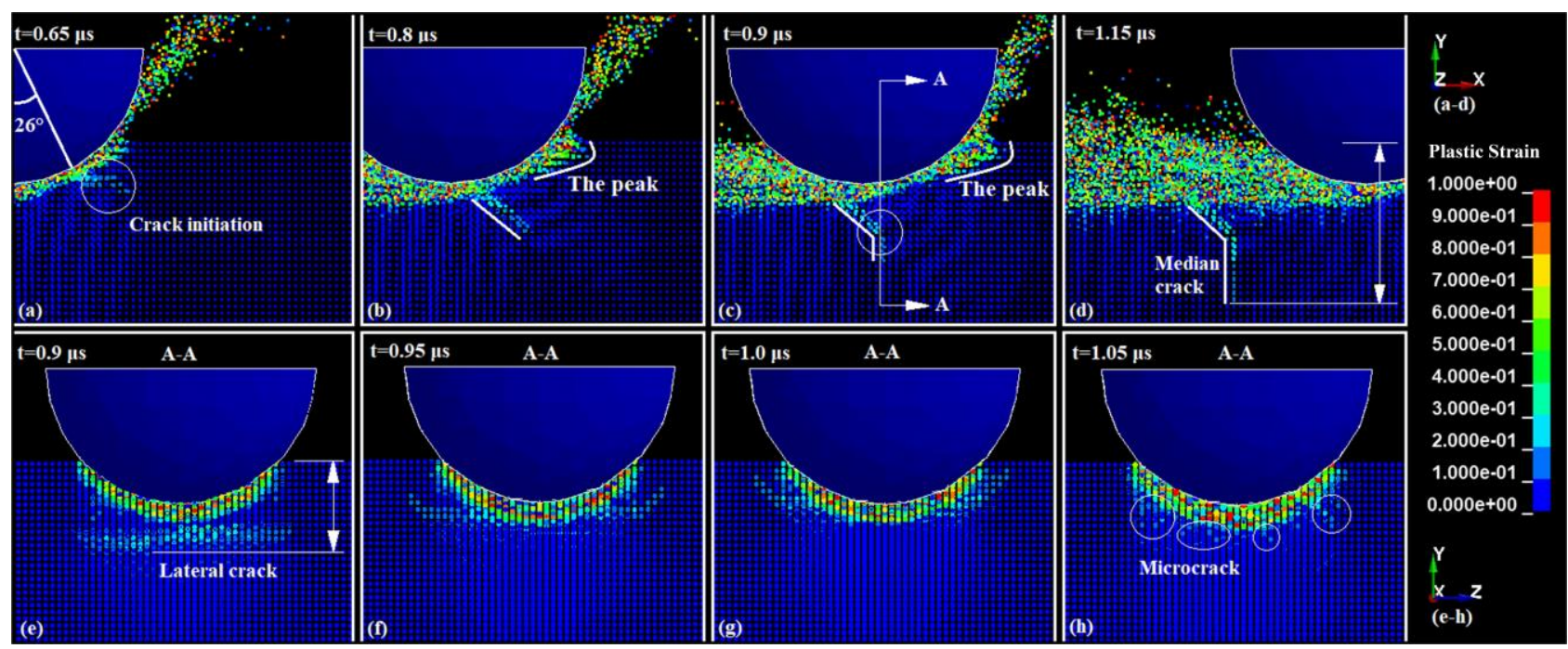

Fig. 6

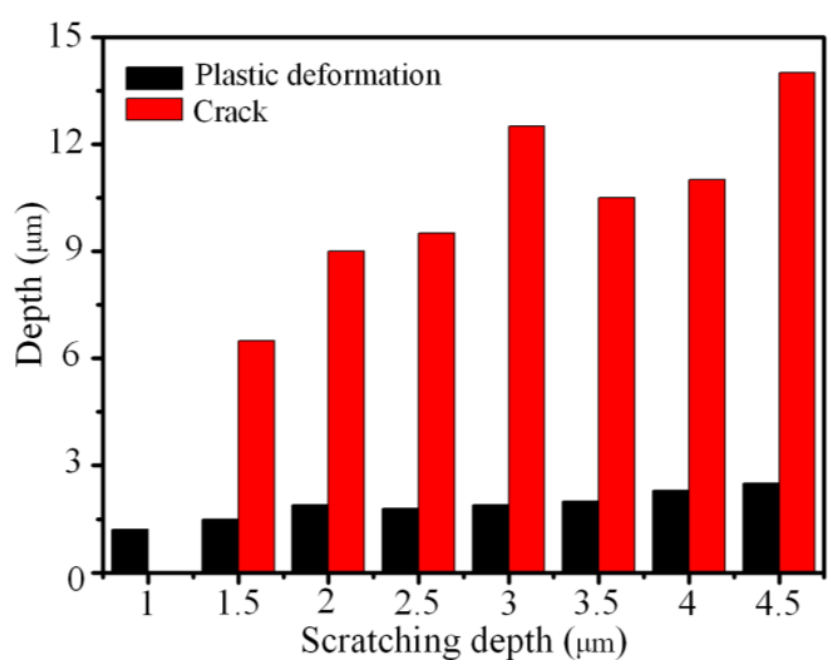

Fig. 7
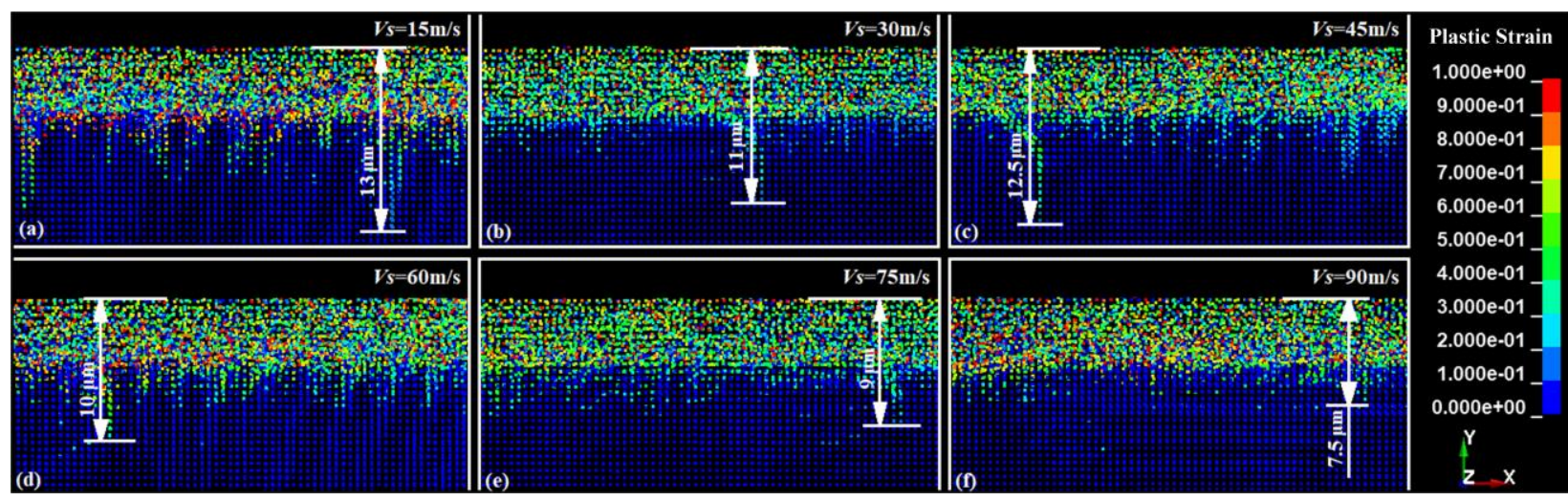

Fig. 8 

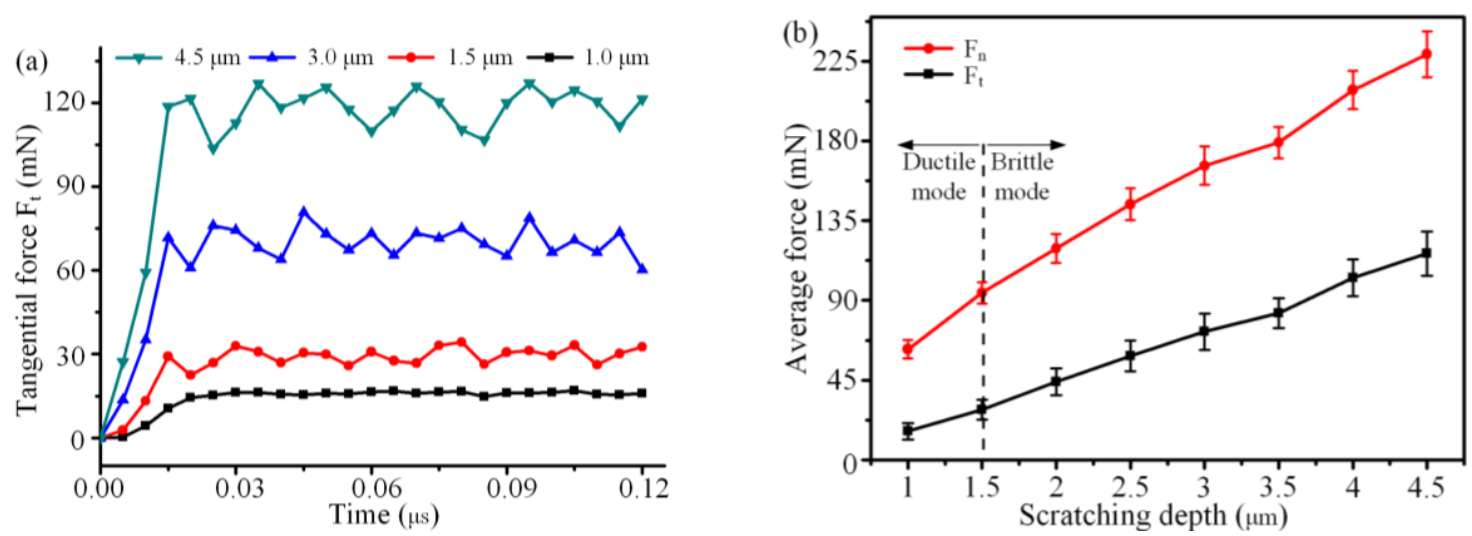

Fig. 9

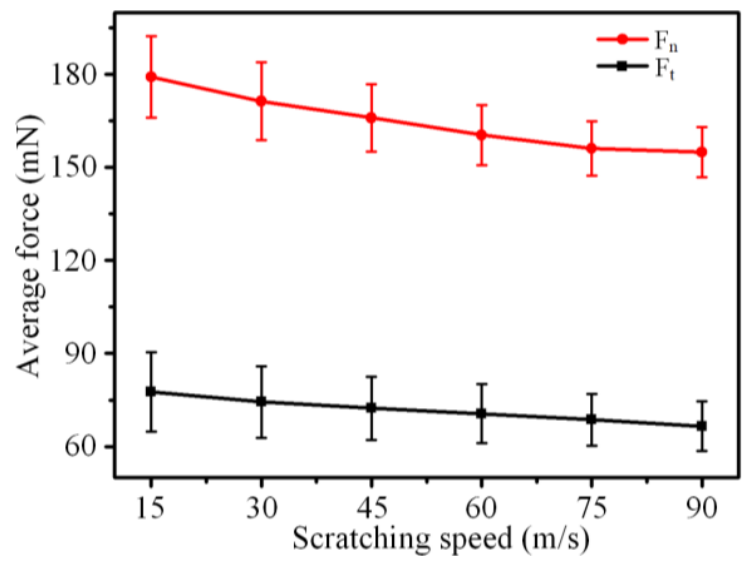

Fig. 10
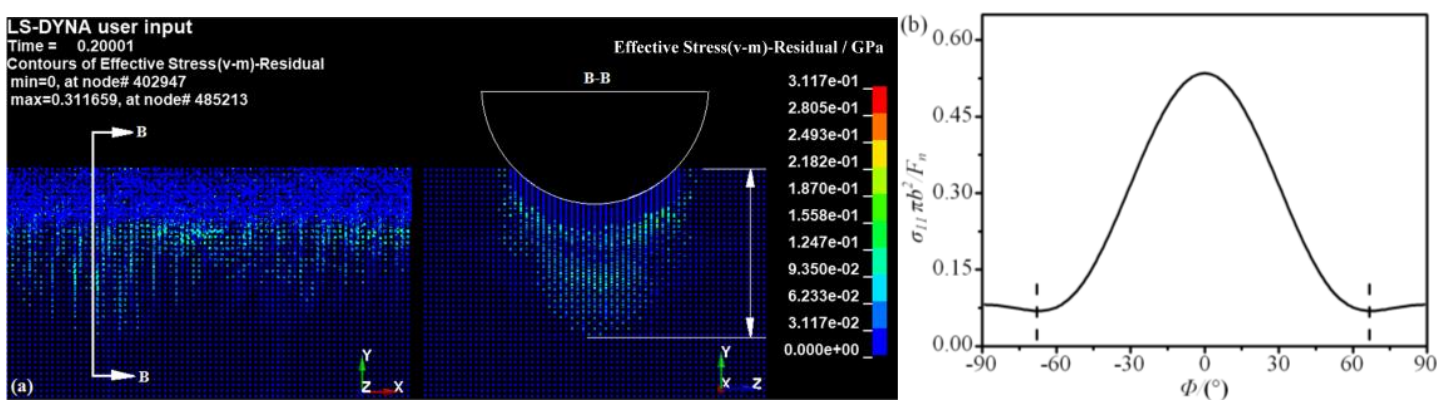

Fig. 11
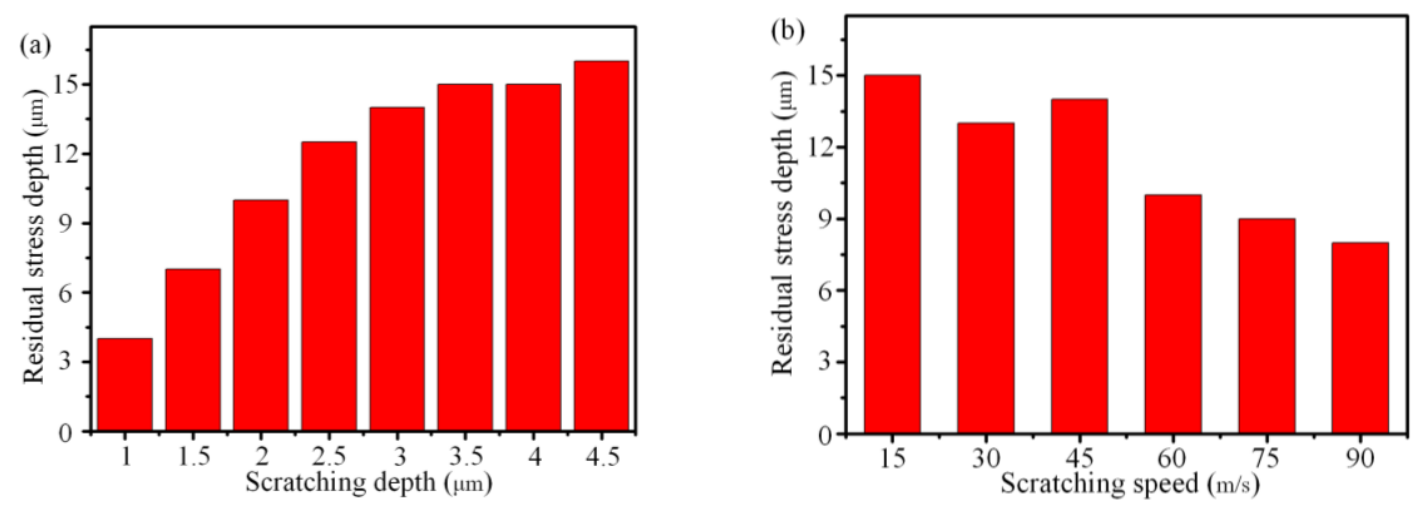

Fig. 12 


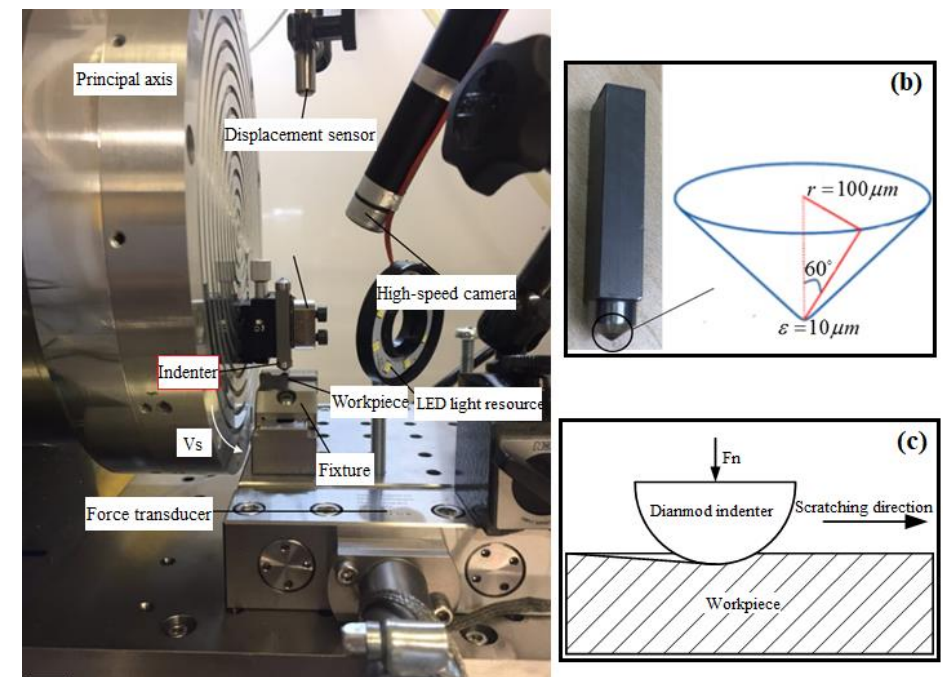

(a)

Fig. 13

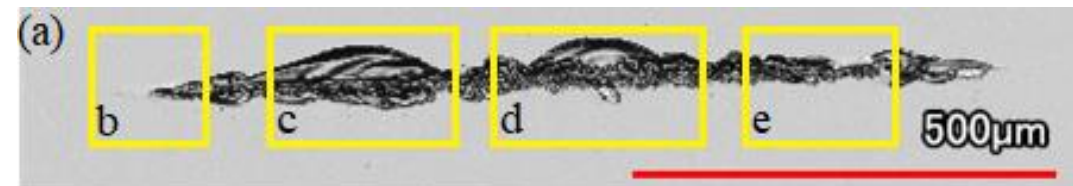

(b) Lateral crack

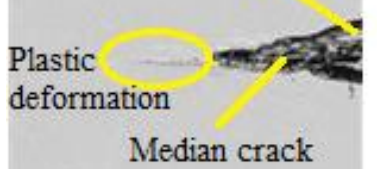

(d) Median crack Lateral çrack

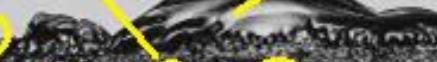

(3)

Hertz crack (c) Lateral crack

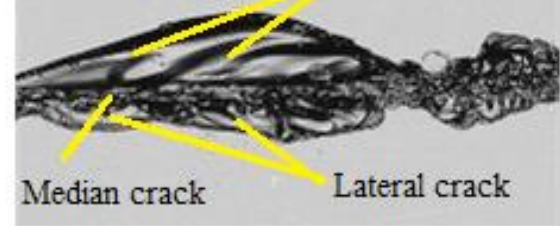

(e)

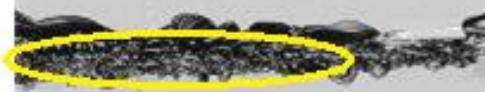

Microcrack

Fig. 14

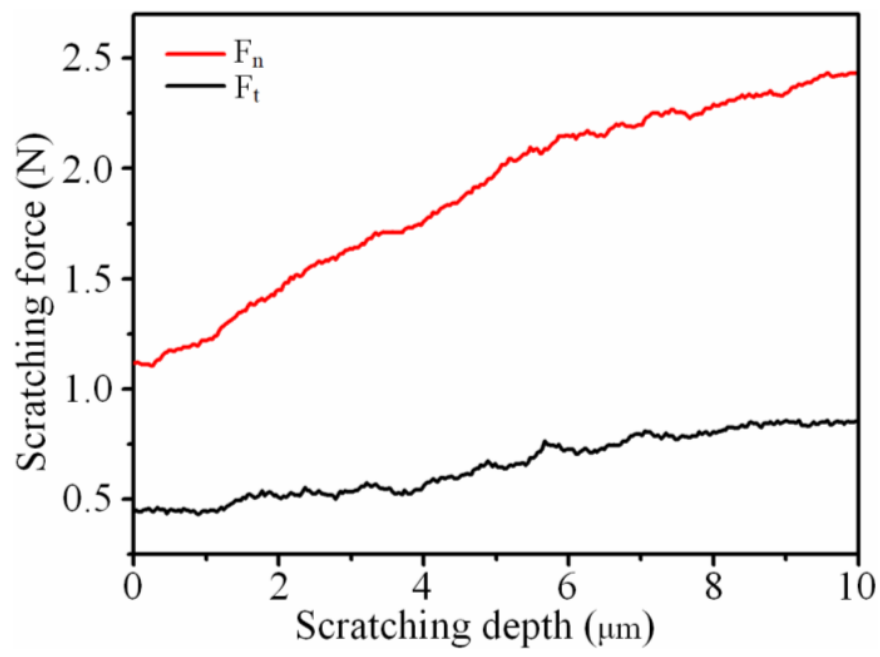

Fig. 15 
Table 1

\begin{tabular}{cccc}
\hline Parameters & Value & Parameters & Value \\
\hline Density & $2.20 \mathrm{~g} \cdot \mathrm{cm}^{-3}$ & Complete strength $(\mathrm{N})$ & 0.75 \\
$\begin{array}{c}\text { Shear modulus } \\
\text { Tensile strength }\end{array}$ & $31 \mathrm{GPa}$ & Hug elastic limit $(\mathrm{HEL})$ & $9 \mathrm{GPa}$ \\
$\begin{array}{c}\text { Standard strength } \\
(\mathrm{A})\end{array}$ & $0.05 \mathrm{GPa}$ & Elastic strain $\left(\mathrm{D}_{1}\right)$ & 0.053 \\
$\begin{array}{c}\text { Fracture strength } \\
(\mathrm{B})\end{array}$ & 0.93 & Elastic strain $\left(\mathrm{D}_{2}\right)$ & 0.85 \\
$\begin{array}{c}\text { Strain rate strength } \\
(\mathrm{C})\end{array}$ & 0.003 & First pressure coefficient & \\
$\begin{array}{c}\left(\mathrm{K}_{1}\right) \\
\text { Pressure index }(\mathrm{M})\end{array}$ & 0.29 & $\left(\mathrm{~K}_{2}\right)$ & $45.4 \mathrm{GPa}$ \\
\end{tabular}

